\title{
A Case Report and Literature Review of Hepatic Follicular Dendritic Cell Sarcoma
}

\author{
Xiaolong Liu, Zirong Liu, Zilin Cui, Yamin Zhang* \\ Department of Hepatobiliary Surgery, Tianjin First Central Hospital, Tianjin, China \\ Email: ^]xl1093@163.com
}

How to cite this paper: Liu, X.L., Liu, Z.R., Cui, Z.L. and Zhang, Y.M. (2017) A Case Report and Literature Review of Hepatic Follicular Dendritic Cell Sarcoma. Case Reports in Clinical Medicine, 6, 157-163. https://doi.org/10.4236/crcm.2017.66016

Received: May 24, 2017

Accepted: June 20, 2017

Published: June 23, 2017

Copyright @ 2017 by authors and Scientific Research Publishing Inc. This work is licensed under the Creative Commons Attribution International License (CC BY 4.0).

http://creativecommons.org/licenses/by/4.0/ (c) (i) Open Access

\begin{abstract}
To investigate the clinical manifestation, imaging features, pathological characteristics, and diagnosis of hepatic follicular dentritic cell sarcoma, a case report combined with literature review was introduced. A large single mass in liver was showed in CT scan. Enhanced CT showed obvious uneven change of liver neoplasm during the arterial phase and the portal vein phase with tortuous disorganized blood vessels. Immumohistochemical staining of CD21, CD23 and EBER was positive. HFDCS is extremely rare. Except for pathologicaldiagnosis by liver biopsy, its preoperative diagnosis rate is extremely low. Its diagnosis is based on the histopathology and immumohistochemistry. HFDCS was first reported by Shek in 1996, and often occurred in women aged 19 - 82 years (with an average age of 46.7 years). Its main clinical manifestations were abdominal pain, abdominal distention, weight loss, anemia, fever, etc. Some patients were asymptomatic.
\end{abstract}

\section{Keywords}

Hepatic, Follicular Dentritic Cell Sarcoma, Immumohistochemical, EBV

\section{Introduction}

The follicular dendritic cell (FDC) belongs to the immune auxiliary system and is an antigen-presenting cell with the strongest known function in the body. Its main functions are antigen capture, processing and presentation, and stimulating $\mathrm{T}$ lymphocytes for proliferation and differentiation. Follicular dendritic cell sarcoma (FDCS) is a low-grade malignancy with an extremely low morbidity that is formed by excessive proliferation of follicular dendritic cells and can occur in any organ except the brain. Therefore, hepatic follicular dendritic cell sarcoma (HFDCS) is extremely rare and often reported as individual cases. The Department of Hepatobiliary Surgery of our hospital cured a HFDCS patient 
whose case is reported herein.

\section{Case Presentation}

A 52-year-old male was admitted in August 2015 due to a huge liver neoplasm found during a physical examination. The patient had sought medical advice at a hospital in Beijing and was diagnosed with follicular dendritic cell sarcoma (FDCS) by liver biopsy pathology. In order to receive further operative treatment, he was admitted to the hepatobiliary surgery department of our hospital. Since the onset, the patient was mentally normal with normal urination and defecation, and had no fever. He lost about $10 \mathrm{KG}$ in nearly eight months. The past had been healthy, denying a history of hypertension and coronary heart disease, denying diabetes history, denying residential history in affected areas. Physical examination showed abdominal distention without gastrointestinal type or peristaltic wave. No subcutaneous varicose vein of abdominal wall, tenderness, rebound tenderness or tension of abdominal muscles was observed. The abdomen was soft. The inferior border of the liver was $5 \mathrm{~cm}$ beneath the rib. The spleen was not felt under the rib. A tympanitic note was found by percussion, with negative sign of ascites and 4/min of borborygmi. On admission, the related inspections were completed. The blood routine examination showed WBC $45.80 \times$ $10^{\wedge} 9 / 1$ (group consultation was conducted by the hematology department before the operation. A leukemoid reaction was considered and protopathy treatment was recommended. After hepatectomy, the indicators recovered, HGB $83 \mathrm{~g} / \mathrm{l}$, PLT $418.00 \times 10^{\wedge} 9 / 1$, NEUTR $92.50 \%$. Detection of the Viral Hepatitis B showed: $\mathrm{HBsAg}(+), \mathrm{HBeAg}(+), \mathrm{HBcAb}(+)$ and the tumor marker carcino-embryonic antigen $1.46 \mathrm{ng} / \mathrm{ml}$, AFP $1.24 \mathrm{ng} / \mathrm{ml}$, and glycoprotein antigen $19930.62 \mathrm{U} / \mathrm{ml}$. Liver reservation experiments showed $15 \mathrm{~min}$ retention rate of ICG (R15): 10.1\%. Plain scan and 4-phase enhanced CT of abdomen showed large flaky low-density shadows in the liver parenchyma (S4, S6-8) of $19.8 \times 17 \times 20.4 \mathrm{~cm}$ with an obscure boundary. The retrohepatic inferior vena cava was constricted and obviously flat. The left hepatic vein was compressed, while the middle and right hepatic veins were not developed. A diagnosis of large malignant spaceoccupying lesion in the liver (involving the middle and right hepatic veins) was made (Figure 1(a), Figure 1(b)).

Due to active preoperative preparation, no surgical contraindication was seen. The patient accepted a resection of the right hepatic trilobites under general anesthesia with endotracheal intubation on August 5, 2015. During the operation, a $30 \times 20 \times 18 \mathrm{~cm}$ tumor with tough texture was seen on the right lobe of the liver. Enlarged lymph nodes were seen beside the biliary tract and were simultaneously dissected. No obvious metastasis was observed in the abdominal cavity, pelvic cavity or on the peritoneum. After the resection, the sample was cut open and a huge grayish yellow nodule of $18.5 \mathrm{~cm}$ diameter was seen (Figure 2). Within the nodule, there were several hemorrhaged areas with a solid fish-flesh-like section. Representative hematoxylin and eosin staining of postoperative pathological examination showed: 1 . Inflammatory pseudotumor-type 


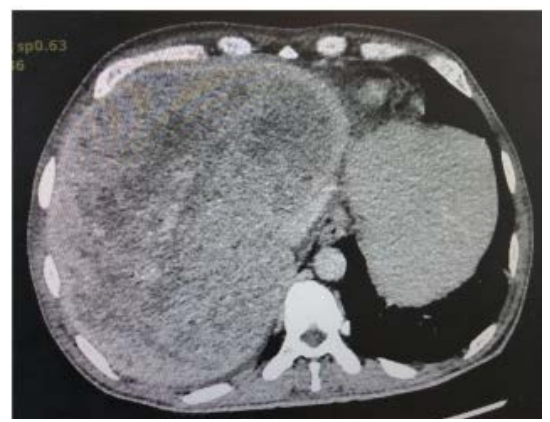

(a)

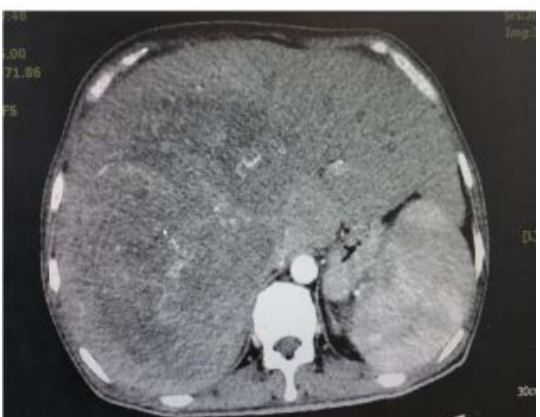

(b)

Figure 1. (a) CT scan showed evagination of shape and profile of the liver. Large flaky low-density shadows were observed in the liver parenchyma (S4, S6-8). (b) Enhanced CT showed obvious uneven change of liver neoplasm during the arterial phase and the portal vein phase with tortuous disorganized blood vessels.

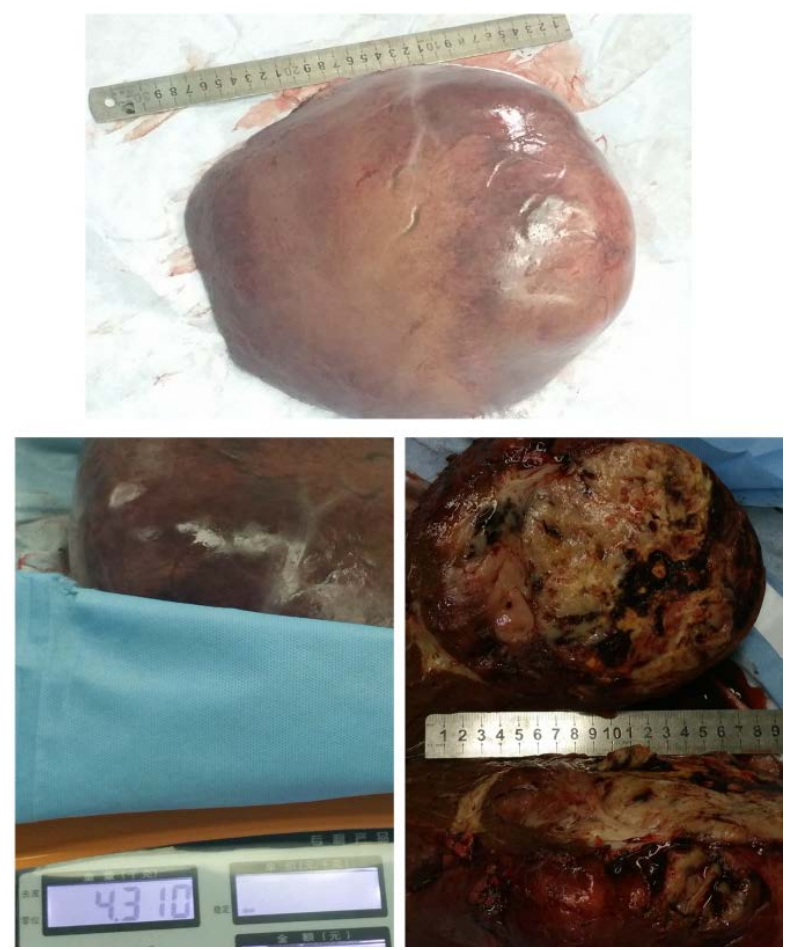

Figure 2. The liver mass was about $30 \times 20 \times 18 \mathrm{~cm}$ with tough texture and weighed about $4.3 \mathrm{~kg}$. After cutting the sample open, a grayish yellow nodule of $18.5 \mathrm{~cm}$ diameter was seen. Within the nodule, there were several hemorrhaged areas with a solid fishflesh-like section.

FDCS. Immumohistochemical staining of CD21, CD23 and EBER were positive; CD20 and CD3 were focal positive; and CD1a, S-100 and CD34 were negative; 2. Castleman disease of lymph nodes with hyperplasia of FDCs. Immumohistochemical staining showed EBER positive. CD21, CD23, CD20 and CD3 were focal positive; CD1a, S-100 and CD34 were negative; 3. Chronic inflammation of gallbladder mucosa (Figure 3). After surgery, giving the liver protection, promoting bile excretion and providing nutritional support in the treatment of liver insufficiency, the situation is getting better. The patient was discharged 15 days 


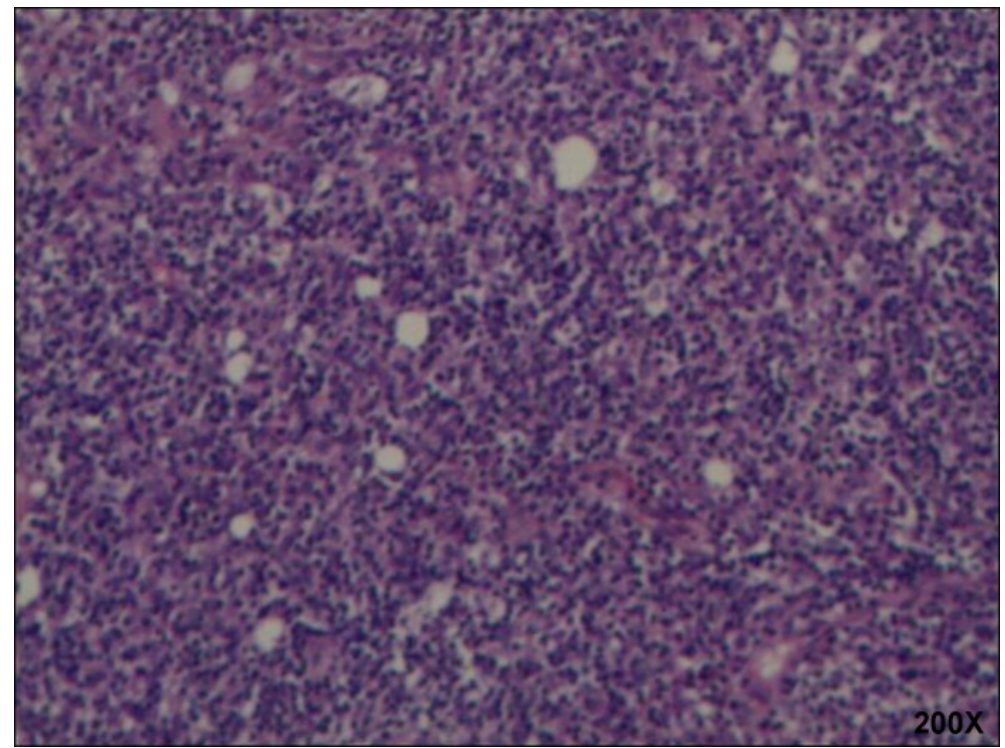

Figure 3. Representative hematoxylin and eosin staining of pathological examination showed inflammatory pseudotumor-type FDCS. Immumohistochemical staining of CD21, CD23 and EBER was positive; CD20 and CD3 was focal positive; and CD1a, S-100 and CD34 was negative.

after surgery with normal liver function. A follow-up abdominal CT examination one year after surgery revealed that no abnormal enhancement of the liver, portal vein and right branch was unobstructed. Liver and kidney function are completely normal.

\section{Discussion}

The follicular dendritic cell (FDC) belongs to the immune auxiliary system and is an antigen-presenting cell with the strongest known function in the body. Its main functions are antigen capture, processing and presentation, and stimulating $\mathrm{T}$ lymphocytes for proliferation and differentiation. FDC is the central link for initiating, controlling and maintaining immune responses, and plays an important role in immunoregulation of body cells and fluids. Follicular dendritic cell sarcoma (FDCS) is a low-grade malignancy with an extremely low morbidity that is formed by excessive proliferation of follicular dendritic cells and can occur in any organ except the brain. According to tumor classification of WHO [1], FDCS is composed of histocytes and FDCs that mostly occur on cervical lymph nodes, often manifest as painless lymphadenectasis and about one-third of cases occur beyond nodes. In 1986, Monda [2] et al. reported four cases of FDCS, all of which occurred in lymph nodes. In 1994, Chan [3] et al. reported two cases of FDCS outside lymph nodes. Thereafter, reports of FDCS cases outside nodes gradually increased, most of which were seen on pars oralispharyngis, while others occurred in stomach, pancreas, spleen, liver, lungs, mammary glands and colon [4] [5].

HFDCS is extremely rare and often reported as individual cases. HFDCS was first reported by Shek [6] et al. in 1996, and often occurred in women aged 19 - 
82 years (with an average age of 46.7 years). Its main clinical manifestations were abdominal pain, abdominal distention, weight loss, anemia, fever, etc. Some patients were asymptomatic.

Pathological characteristics of FDCS included lesion diameter of up to $20 \mathrm{~cm}$, node-like or lobulated section, punctiform necrosis and hemorrhage. Under microscopy, growth patterns of fasciculation, storiform, swirl, and diffusibility could be seen. Tumor cells were shuttle-like or oval with obscure boundaries and the cytoplasm showed mild acidophilia. Nuclei were shuttle-like, round or oval with clear karyotheca and micronucleoli. Within the tumor parenchyma, mature small lymphocyte infiltration was unevenly dispersed, while some areas showed numerous lymphocytes enclosed in blood vessels and generated a sleeve structure. The lymphoid tissue around the tumor showed hyaline-vascular Castleman's disease (HVCD). Some studies [5] suggested that HVCD might be a precancerous lesion of FDCS. FDCS could express one or numerous FDC markers including CD21, CD23, CD35, agglutinin, VIM, etc. CD21 and CD35 were generally positive in most FDCS cases [7] [8]. Epithelial membrane antigen (EMA), S-100 protein and CD45 were partially expressed, while CD1a, CD68 and desmin were rarely expressed [4] [9]. EBv could be tested in some FDCS patients, especially in inflammatory pseudotumor-type HFDCS patients with a higher positive rate. The positive rate of EBv in HFDCS patients was 63\%. The in-situ hybridization result of EBV encoded small RNA (EBER) of atypia cells and some shuttle-like cells were positive. EBER testing was recommended during diagnosis of HFDCS.

The invasion of HFDCS is extremely rare, so its treatment is limited and no treatment guideline can be used as a reference. As it usually manifests inertly and is similar to soft tissue sarcoma of low to mid malignancy, tumors of most patients can be completely resected in combination with postoperative chemotherapy or radiotherapy. Chemotherapy is also given to patients who are unable to or refuse surgery. Most of them are treated with a combined regimen based on the Non-Hodgkin lymphoma chemotherapy regimen, namely the CHOP regimen (a 21-day cycle of ifosfamide injection, epirubicin injection, vincristine injection and prednisone) for 3 - 6 cycles. Pas [10] et al. performed a retrospectiveanalysis of 184 FDCS cases, and showed that the recurrencerate of patients who received an excision without any adjuvant therapy was $40 \%$, while that of patients who received an excision with adjuvant therapy was $32.6 \%$ indicating that chemotherapy and radiotherapy did not enhance the postoperative survival rate of patients.

\section{Conclusion}

In conclusion, HFDCS is extremely rare. Except for pathological diagnosis by liver biopsy, its preoperative diagnosis rate is extremely low. A tumor diameter $>$ $6 \mathrm{~cm}$ is considered to be an important factor for poor prognosis. In this case, with liver biopsy before the surgery, the patient had a clear pathological diagnosis and the tumor diameter was $>6 \mathrm{~cm}$. After partial hepatectomy, the patient 
was admitted to a local hospital for sequential treatment. The patient's condition is currently stable. During outpatient reexamination at our hospital, no metastasis or recurrence was observed in enhanced CT of the abdomen. The patient has not yet received radiotherapy or chemotherapy. Further follow-up is needed for long-term prognosis.

\section{References}

[1] Swerdllow, S., Campo, E. and Harris, N.L. (2008) WHO Classification of Tumours of Haematopoietic and Lymphoid Tissues. IARC Press, France.

[2] Monda, L., Warnke, R. and Rosai, J. (1986) A Primary Lymph Node Malignancy with Features Suggestive of Dendritic Reticulum Cell Differentiation. A Report of 4 Cases. American Journal of Pathology, 122, 562-572.

[3] Chan, J.K., Tsang, W.Y., Ng, C.S., Tang, S.K., Yu, H.C. and Lee, A.W. (1994) Follicular Dendritic Cell Tumors of the Oral Cavity. American Journal of Surgical Pathology, 18, 148-157. https://doi.org/10.1097/00000478-199402000-00004

[4] Martins, P.N., Reddy, S., Martins, A.B. and Facciuto, M. (2011) Follicular Dendritic Cell Sarcoma of the Liver: Unusual Presentation of a Rare Tumor and Literature Review. Hepatobiliary \& Pancreatic Diseases International, 10, 443-445. https://doi.org/10.1016/S1499-3872(11)60076-3

[5] Kim, H., Park, C.M., Jeon, Y.K., Yoo Ie, R., Song, S.W., Goo, J.M. and Lee, H.J. (2012) Computed Tomography and 18F-Fluoro-2-Deoxyglucose Positron Emission Tomography Findings of Primary Pulmonary Follicular Dendritic Cell Sarcoma: Case Report and a Literature Review. Journal of Thoracic Imaging, 27, W94-W96. https://doi.org/10.1097/rti.0b013e318220309f

[6] Shek, T.W., Ho, F.C., Ng, I.O., Chan, A.C., Ma, L. and Srivastava, G. (1996) Follicular Dendritic Cell Tumor of the Liver. Evidence for an Epstein-Barr Virus-Related Clonal Proliferation of Follicular Dendritic Cells. American Journal of Surgical Pathology, 20, 313-324. https://doi.org/10.1097/00000478-199603000-00008

[7] Shia, J., Chen, W., Tang, L.H., Carlson, D.L., Qin, J., Guillem, J.G., Nobrega, J., Wong, W.D. and Klimstra, D.S. (2006) Extranodal Follicular Dendritic Cell Sarcoma: Clinical, Pathologic, and Histogenetic Characteristics of an Underrecognized Disease Entity. Virchows Archiv, 449, 148-158.

https://doi.org/10.1007/s00428-006-0231-4

[8] Satoh, K., Hibi, G., Yamamoto, Y., Urano, M., Kuroda, M. and Nakamura, S. (2003) Follicular Dendritic Cell Tumor in the Oro-Pharyngeal Region: Report of a Case and a Review of the Literature. Oral Oncology, 39, 415-419. https://doi.org/10.1016/S1368-8375(02)00138-0

[9] Fareed, M.M., Memon, M.A., Rashid, A., Furrukh, M., Ahmed, S., Ghouri, A.R., Khan, A. and Asghar, A.S. (2011) Follicular Dendritic Cell Sarcoma of the Neck with Pulmonary Metastases. J Coll Physicians Surg Pak, 21, 561-563.

[10] De Pas, T., Spitaleri, G., Pruneri, G., Curigliano, G., Noberasco, C., Luini, A., Andreoni, B., Testori, A. and De Braud, F. (2008) Dendritic Cell Sarcoma: An Analytic Overview of the Literature and Presentation of Original Five Cases. Critical Reviews in Oncology Hematology, 65, 1-7. https://doi.org/10.1016/j.critrevonc.2007.06.003 


\section{Appendix}

\section{Clinical Trial Ethics Committee of Tianjin First Central Hospital}

Certificate No: E2017011L

\begin{tabular}{|c|c|c|c|c|c|}
\hline \multirow{2}{*}{$\begin{array}{l}\text { Title } \\
\text { Classification of } \\
\text { research }\end{array}$} & \multicolumn{5}{|c|}{ A case report and literature review of hepatic follicular dendritic cell sarcoma } \\
\hline & $\square$ Drug $\square$ Medical Equipment & $\square$ Diagnostic Reagent & $\square$ New Technology & - Scientific Research $\square \mathrm{T}$ & hesis \\
\hline Department & \multicolumn{3}{|c|}{ Department of Organ Transplant Center in Tianjin First Central Hospital } & Items of application & Ethic review \\
\hline Person in charge & Xiaolong Liu & Professional title & Chief physician & Telephone & 13102190212 \\
\hline \multirow{2}{*}{$\begin{array}{l}\text { Examination } \\
\text { contents }\end{array}$} & \multicolumn{5}{|c|}{ Researcher qualifications: $\sqrt{ }$ meet the requirements } \\
\hline & \multicolumn{5}{|c|}{ The methods and contents of obtaining informed consent: $\sqrt{ }$ Appropriate } \\
\hline $\begin{array}{l}\text { Ethical Committee } \\
\text { statement }\end{array}$ & \multicolumn{5}{|c|}{$\begin{array}{l}\text { The composition and operation procedure of the ethics committee are in accordance with the clinical trial } \\
\text { management regulations and relevant laws and regulations of the state. }\end{array}$} \\
\hline \multirow{2}{*}{ Voting results } & Agreement & Revision & Reject & Waiver & \\
\hline & 17 人 & 0 人 & 0 人 & 0 人 & \\
\hline
\end{tabular}

\section{Ethical review comments:}

The review of the "A case report and literature review of hepatic follicular dendritic cell sarcoma" by the ethics committee of Tianjin First Central Hospital: The study aimed to investigate the clinical, pathological and radiological characteristics, and diagnosis of hepatic follicular dentritic cell sarcoma. The content is not related to the patient's name, hospital number and other identification information, members of Ethics Committee unanimously agreed.

Signature of Chairman: -

Ethics Committee Of Tianjin First Central Hospital

Submit or recommend next manuscript to SCIRP and we will provide best service for you:

Accepting pre-submission inquiries through Email, Facebook, LinkedIn, Twitter, etc. A wide selection of journals (inclusive of 9 subjects, more than 200 journals)

Providing 24-hour high-quality service

User-friendly online submission system

Fair and swift peer-review system

Efficient typesetting and proofreading procedure

Display of the result of downloads and visits, as well as the number of cited articles

Maximum dissemination of your research work

Submit your manuscript at: http://papersubmission.scirp.org/

Or contact crcm@scirp.org 